\title{
Cultivating STEAM Literacy: Emphasizing the Implementation of the Arts through Reading Practices Supporting the Asian Diaspora
}

\author{
Jennifer C. Park | ORCID: 0000-0003-4327-2201 \\ Rossier School of Education, University of Southern California, \\ Los Angeles, CA 90089, USA \\ jennifcp@usc.edu
}

\begin{abstract}
This paper explores the cultivation of STEAM literacy through the employment of practices derived from traditional reading strategies. This teaching and learning framework focuses on utilizing multimodal texts to increase exposure and opportunities for students to creatively explore diverse realms of STEM through the arts. Featuring studentcentered endeavors through self-selected texts and in-class reading practices followed by tiered scaffolded discourse engagements, this framework initiates greater interest, autonomy, and culturally and linguistically authentic practices enhancing STEAM literacy. Embedded in the implications is the deconstruction of frequently aggregated STEM data that "overrepresents" the Asian demographic. Using the lens of the model minority myth, this paper attempts to disaggregate the Asian category, illuminating the actual diaspora that makes up the Asian and Asian American communities, many of which are not represented in STEM fields. Through more reading opportunities and fostering discourse practices, the arts contribute greater inclusion, cultivating STEAM literacy for all students.
\end{abstract}

\section{Keywords}

STEAM - STEAM literacy - multimodal texts - reading - Asian diaspora 
The science, technology, engineering, and math (STEM) employment sector has continued to develop in the 21st century, expanding the opportunities for career choices this field offers. Today, STEM education incorporates a variety of instructional approaches that generate creative ways to foster engage, innovate, and create deeper understandings of the interconnected world. This paper focuses on one of these approaches, which is STEAM (science, technology, engineering, the arts, and math) education. STEAM education is a derivative of STEM that incorporates the arts (Yakman, 2008) providing learners with greater authentic and culturally relevant, real-world applications (Dell'Erba, 2019; Chu, Martin, \& Park, 2018). StEAM education is an experimental and experiential learning pedagogy that scaffolds and builds knowledge and skill sets on a long-term trajectory, aiming to construct critical habits of mind that support the application of knowledge through integrated context-based projects (NSTA, 2012). Implementation does not simply focus on STEM topics while accentuating the arts as an add-on, but holistically engineers all topics as an interdisciplinary unit. The arts are subcategorized as social, language, physical, musical, and fine arts which should be integrated into STEM technical and pedagogical practices rather than used as mere auxiliaries. This integrative aspect of STEAM allows "science" to be studied not as a group of separate subjects, but as interconnected practices that enhance problem solving, critical thinking, collaborative inquiry, authentic engagements, and "affective aspects of learning" (Chu, Martin, \& Park, 2018, p. 1252).

The inclusion of the arts in STEAM can foster characteristics that artists possess, including being "keen observers, have good reasoning skills", being able to "compare and contrast artistic element integration across multiple pieces of work" and "use evidence to support their critiques, and practice argument[ation]" (Zygouris-Coe, 2015, p. 39). STEAM pedagogy is holistically supportive of encouraging learning through community and empathetic developments for all citizens (Yakman, 2012). Milgrom-Elcott (2019) mentions that STEAM approaches have created "a haven for the otherwise marginalized" (para. 3) as they open potential doors of opportunity through a crossdisciplinary approach. STEAM education has also been identified as a useful approach for connecting diverse student populations with STEM related content. Arts integration allows diverse students to learn in meaningful, inclusive ways, giving all students "opportunities to see the connection between the content [being] stud[ied] and the application of that content" (NSTA, 2012, para. 1). This is because STEAM education takes a guided-inquiry approach to creatively investigate scenarios that exist in real and hypothetical situations, 
involving cultural, linguistic, and social aspects of the arts. These innovative ways of interacting with STEAM create a positive feedback response that fuels real, practical, and applicable connections made both inside and outside the classroom. These studies suggest there is a real need for and benefit to developing STEAM education learning opportunities for all students as this approach prepares students for participation in a globally connected economy and world. However, there are some challenges to implementing STEAM education in schools.

This paper seeks to introduce an aspect of arts integration related to reading and literacy that can be effective in supporting diverse learners to engage with STEM content through STEAM and that may help to overcome some challenges with implementing STEAM in schools. Creating greater opportunities for students to self-explore multimodal texts in the classroom and encouraging students to participate in STEAM reading and discourse spaces, teachers can increase students' ST EAM literacy, which can improve their ability to make interdisciplinary connections. Cox (2012) emphasizes that "inquiry-based, discovery-focused science instruction is widely viewed as best practice ... when it is integrated with other areas of curriculum such as reading" (para. 1). To facilitate these practices in STEAM classrooms, this paper introduces a teaching and learning framework to increase literacy through scaffolded reading and discourse engagements using multimodal texts.

Second, this paper focuses particular attention on how a greater utilization of multimodal texts in the classroom could be useful in supporting cultural and linguistic minorities in the United States - to be more successful to learn STEM content by inviting greater pedagogical understanding and culturally and linguistically relevant practices for diverse diasporas, especially students who identify as Asian and Asian American. Although the identities and experiences of members of the Asian diaspora in the United States are richly diverse, the experiences of Asian immigrants and Asian Americans are frequently collapsed into a single statistical figure which often shows Asian students to be high achievers in STEM, especially related to students of other races. This study aims to disrupt the perception that Asians and Asian Americans are "overrepresented" in STEM in an effort to draw more attention to the ways in which STEAM education, with a language arts and literacy focus, could improve learning opportunities for all individual that make up the Asian diaspora.

The challenges in STEAM pedagogy that need to be overcome are three-fold: an unclear definition of what is considered "the arts" in STEAM, misconceptions 
of the arts-integrated STEM instructional practices, and unconvinced and unprepared teachers. Definitions and descriptions of STEAM education have been inexact. Commonly sT EAM is described as bringing "too much fluff" [to] and "dilut[ing] the essential need and focus" (May, 2015, para. 3) of robust and rigorous STEM curriculum that in which the arts appears as disconnected activities that merely artistically enhances the presentation of STEM. The centralized misconception is that the implementation of the arts is an unnecessary attachment in the form of music, dance, or most likely, fine arts. In addition, STEAM has still been clumped together with STEM as one entity, perpetuating the misconception and illustrating a great lack of awareness of the difference between the two. Along with the unclear descriptions of what is STEAM, approaches to STEAM instruction have been segregated and not well planned to purposively implement holistic content. The interdisciplinary and transdisciplinary purpose of STEAM has not been practiced; rather, subjects have been siloed and imbalanced when employed, causing multiple subjects to be taught while adding the arts to incorporate "hands-on learning." With limited professional development and STEAM training, teachers find it difficult to successfully integrate STEM with the arts, "needing more support in seeking experts outside of their content area ... [and] building connections between their content area and the expressive arts" (Quigley \& Herro, 2016, p. 424). Although teachers may be optimistic about STEAM, many do not believe "that the benefits are commensurate with the amount of time and effort needed to prepare steAm lessons" (Chu, Martin, \& Park, 2018, p. 1253). The awareness and creation of integrated STEAM are challenging for teachers, especially if their areas of expertise do not align. Taken altogether, these challenges generate a burden for teachers to effectively facilitate STEM disciplines across the curriculum, consequently resulting in decreased real-world relevancy of STEAM and dulling interest levels of learners. In the sections that follow, arts integration in the form of multimodal literacy is introduced as a potential way to overcome challenges for teachers and their students.

\section{3}

\section{Theoretical Framework}

The centralized approach considered in this paper focuses on new literacy practices aimed at enhancing K-12 STEAM by expanding self-directed reading opportunities. Implementation of the new literacy theory to STEAM can enhance the diverse methods of fostering and encouraging active learning practices for students in the classroom and in their surrounding communities. New literacy studies, which go beyond just reading and writing, have included the production and consumption of meaning informed by cultural and 
linguistic contexts. According to the National Council of Teachers of English [NCTE] (2013), implementation of new literacies with multimodal texts supports the development of the following skills:

- Manage, analyze, and synthesize multiple streams of simultaneous information

- Create, critique, analyze, and evaluate multimedia texts

- Develop proficiency and fluency with the tools of technology

- Build intentional cross-cultural connections and relationships with others so problems can be posed and solved collaboratively, and independent thought can be strengthened

- Design and share information for global communities to meet a variety of purposes.

Understanding STEAM education through the new literacy studies lens transforms the teaching and learning approach and highlights the inclusive development of STEAM literacy through the use of multimodal texts that increase greater points of access for all learners. Although extensive research has represented the importance of developing literacy in both STEAM and in reading and writing, they have remained largely isolated from one another or not explicitly tied. Mpofu (2019) underlined experiences in STEM disciplines that are frustrating and unsuccessful due to the inaccessibility of the content, stating that "STEM education should be expanded to embrace and integrate with the disciplines of the arts in order to facilitate and promote accessibility of sTEM learning" (Section 3.4). Furthermore, Hwang and Taylor's study (2016) described the positive influences of arts-incorporated STЕM as the inclusion provides greater accessible entry points for students to express their understanding and interpretation of STEM concepts. Whether students are culturally and/or linguistically diverse or have specific needs to accommodate their learning, STEAM crafts motivational ways to engage all learners through manipulation of content through creative, critical, and constructive means. The sections that follow suggest how literacy and STEAM standards could be better connected to language learning in K-12 classroom contexts.

\subsection{Connecting Literacy Standards, STEAM Standards, and Language Learning}

In this section, how curriculum standards in the United States that support STEM learning and language arts can be connected to support language learners in the context of STEAM education are described. In the United States, the Next Generation Science Standards (NGSS) were created as integrated benchmarks that are rich in content and that engage students in cross-disciplinary practice (NGSS, n.d.). Three distinct dimensions make up the NGSS, these 
include: disciplinary core ideas (multiple sciences and engineering), crosscutting concepts (four domains of science), and science and engineering practices (investigative, inquiry-based practices). In the state of California, where this research is contextualized, the Common CoreStateStandards (cCss), have been adopted which include standards that address English language arts (ELA) and English language development (ELD). The literacy components in these standards support students to meet particular challenges related to reading, writing, speaking, and listening and the standards pay close attention to informational, comprehensive, and critical reading strategies (CDE, 2013). A third component, called college and career readiness (CCR) anchors for literacy (Department of Defense Education Activity, n.d.), which are embedded within CCSs and also overlap with key expectations in the NGSs. These integrated standards set expectations for cross-disciplinary and integrated literacy skills.

\section{2 $\quad$ STEAM Literacy and Benefits of Multimodal Texts for Language Learners}

In this section, the integration of reading in STEAM classrooms as a pedagogical approach for developing STEAM literacy skills that support the integration of the NGSS, CCSS, and CCR standards is introduced. This study introduces the concept of STEAM literacy which aims to improve students' reading by exposing them to intentional reading of STEAM related texts while providing explicit scaffolding techniques through tiered discourse to support students to improve literacy skills and STEM content understanding. Derived from a methodology first introduced in the 197os in the United States called sustained silent reading (SSR) (Meyers, 1998), STEAM literacy seeks to integrate reading in the STEAM class while offering opportunities for students to discuss connections between themselves, the text, and the world around them. The initial goal was for students to engage in sustained reading during an allotted time frame while reading self-selected materials. The traditional approach to implementing SSR in class followed two simple rules: a) students select a book of choice (to be read for pleasure) and b) students read silently for 10-20 minutes. The choice of texts could vary, ranging from books and magazines to textbooks and newspapers. The purpose was for students to continuously read and attempt to finish a book of choice.

Due to advances in technology since the development of the ssR method, the selection of texts students can choose has greatly expanded. This increased the availability of multimodal STEAM related texts providing diverse opportunities for students to explore STEAM through their preferred modalities - visual, audio, linguistic, and/or kinesthetic. These options can enrich the reading 
experiences for students in multiple ways, which can diversify and amplify motivation to read about STEAM content. Multimodal texts offers opportunities to foster students' comprehension as multiple representations of content including "visual (still image) written language, and spatial modes" (Victoria State Government, 2018, para. 2) can support different learning modalities. Another benefit to utilizing multimodal texts is it widens opportunities and accessibility for students to gain greater autonomy in the classroom while increasing their literacy levels. SSR has been found to help students develop habits of mind and practice that can increases fluency, vocabulary development, and reading comprehension (Hadler, 2015). Over time these habits of mind can support students to be active readers of content aligned to their own interests, both in and outside the classroom.

Eventually, the SSR method was revised to included scaffolded silent reading (ScSR). ScSR was developed to address issues about the "conspicuous absence of teacher and student interactions around the reading of texts" and "the lack of teacher monitoring and accountability for whether or not students are actually reading" during the allotted silent time (Reutzel, Fawson, \& Smith, 2008, p. 195). In the ScSR method, the teacher periodically facilitates dialogue with students to guide and actively interact with individuals to encourage them to maintain silent reading while also providing the necessary "support, guidance, structure, accountability, and monitoring” (Reutzel, Fawson, \& Smith, 2008, p. 196). ScSR increases accountability, which heightens the expectations of SSR time making it effective and beneficial. Kaczmarek (2016) argues that "sтEM disciplines require the interpretation of technical texts, a vast knowledge of content specific vocabulary, critical thinking, and the ability to clearly communicate these complex concepts to others verbally and in writing" (p. 3). Studies have shown that the more one reads, the more language input is processed, which supports language acquisition. Krashen (2004) argued that indepth reading in any selected topic of choice will provide greater exposure and optimal input to a tremendous amount of content, linguistic acquisition, and literacy-based skill sets, including critical thinking, creativity, and the ability to recall and connect "old and new" concepts. Thus, developing good reading habits in STEAM are needed supporting learners to develop STEM conceptual understanding.

This is especially true for language learner students. Coupled together, SSR and ScSR, offer two complimentary approaches to reading that can support a student-directed exploration of STEAM content. The key to ScSR is the function of scaffolding in supporting habits of reading, language development, and authentic student-centered connections to STEAM. The teaching and learning framework developed to increase STEAM literacy emphasizes the 
opportunity students have to self-select reading material as a springboard for learning about STEAM topics related to their own interests and motivations to learn. Additionally, reading materials selected by students pursuing their own interests, rather than extracting information from dense textbooks and predeveloped labs from teachers, has long-term benefits to promoting autonomy in being able to retrieve relevant information. Student-initiated reading can motivate and increase literacy skills on multiple levels.

\subsection{Structuring Independent Reading and Scaffolding Practices for STEAM Literacy}

The power of reading comes from the interconnected knowledge and literacy skills that students can use across all disciplines to enhance their overall comprehension. The goal of fostering STEAM literacy in the classroom is to cultivate good, structured reading habits that build knowledge foundations and foster equitable learning opportunities for all students. In the sections that follow, a reading-focused teaching and learning framework designed to foster students' steam literacy are introduced. Promoting reading to learn STEAm by combining SSR and ScSR practices can extend practical support for improving literacy for all learners, but especially for language learners. The following sections introduce practical ways to creating a STEAM library and how to facilitate scaffolded STEAM discourse through tiered practices. Teachers and students must be active participants in the development of positive habits of mind to nurture STEAM literacy. This section aims to describe and encourage reading practices that elementary school teachers can adapt into the K-6 classroom.

\subsubsection{Selecting and Evaluating High Quality, Multimodal steAm Texts}

Although implementing reading practices each day as part of STEAM lessons can be difficult, the long-term benefits for students are useful to consider. An essential first step is to provide students with a library of multimodal text options that are accessible to and interesting for a wider range of students (Von Sprecken \& Krashen, 1998). Teachers can begin by creating a STEAM library of a large variety of texts and then invite students to also take part in selecting what would be appropriate for the library. The types of multimodal texts offered in the classroom library will need to be assessed and aligned to the STEAM related content standards (including CCSS, NGSS, and CCR). In addition, the texts need to be representative of diverse perspectives and experiences. To select texts with authentic STEAM alignment and that are also of high quality with good reliability, it is recommended that teachers introduce the use of a reflective checklist developed to select good quality materials in 
the classroom. This checklist emphasizes multimodal texts and inclusive content. It was adapted from earlier research about how to select good quality science reading text by Buxton and Austin (2003) and Donovan and Smolkin (2002) (see Table 1).

TABLE 1 Adapted checklist and reflective tool for teachers to collaboratively utilize when selecting multimodal texts to incorporate in their classroom STEAM library

\begin{tabular}{|c|c|c|}
\hline Reflective questions & $\mathrm{Y} / \mathrm{N}$ & $\begin{array}{l}\text { If no, how will you scaffold } \\
\text { this element in the tiered } \\
\text { discourse? }\end{array}$ \\
\hline
\end{tabular}

Does the text contain significant or

relatable STEAM content? Is the content

presented explicitly and/or implicitly

$\square \mathrm{N}$

(ranging in contextualization and dif-

ficulty levels)?

Does the author assume that the reader $\quad \square \mathrm{Y}$
has a vast amount of prior knowledge
about purpose, concepts, or vocabulary $\quad \square \mathrm{N}$
on STEAM?

Are active inquiry-based approaches

$\square \mathrm{Y}$

addressed adequately with the inclusion

of real-life, authentic [applicable] STEAM

examples?

Is the information carefully introduced

$\square \mathrm{Y}$

and scaffolded to align to appropriate

standards and reading levels (at

$\square \mathrm{N}$

or above)?

Are STEAm specific vocabulary words

$\square \mathrm{Y}$

included within the text, explained,

presented, and documented appro-

$\square \mathrm{N}$

priately (consider diverse proficiency

levels)? 
TABLE 1 Adapted checklist and reflective tool for teachers to collaboratively utilize when selecting multimodal texts to incorporate in their classroom sTEAM library (cont.)

Reflective questions Y/N If no, how will you scaffold this element in the tiered discourse?

Is the text's language level at or near $\square \mathrm{Y}$ their grade/language proficiency aiming toward students' Zone of Proximal $\square \mathrm{N}$ Development (Vygotsky, 1978)?

Is the text relevant and meaningful $\square \mathrm{Y}$ to real-world ideas, processes, actions, etc.? $\square \mathrm{N}$

Is the text well organized with suitable $\quad \square \mathrm{Y}$ illustrations and other access features such as headings, sidebars, captions, $\square \mathrm{N}$ or illustrations?

Does the text respect the reader/viewer $\square \mathrm{Y}$ by presenting positive ethical and cultural values, especially inclusive of gen$\square \mathrm{N}$ der, racial, and linguistic representation?

Are women and minoritized people $\square \mathrm{Y}$ groups presented positively, and are stereotypes avoided? $\square \mathrm{N}$

Are the writing/production styles, usage $\square \mathrm{Y}$ of pictures/visuals, character and setting, and STEAM integration diverse?

* Adopted and adapted from Buxton and Austin (2003) and Donovan and Smolkin (2002) (as cited in Atkinson, Matusevich, and Huber, 2009).

Teachers are encouraged to model for students how to select and recommend new texts using the checklist to ensure that selected texts for ScSR are high quality while also being interesting to students. In addition, this collaboration 
creates meaningful connections to STEM in the real world and expands students' sт EAM literacy opportunities. The checklist contains 11 questions that critically consider the reliability and validity of STEAM-focused texts. The checklist helps to ensure that texts contain STEAM content and is easily accessible for students, illustrating authentic stories through the arts and has inclusive representations. Teachers are encouraged to provide supplemental texts and a scaffolded approach to dialogue about STEAM content when evaluation in a few categories are limited.

\subsubsection{Fostering Habits of Mind through ScSR}

Habits of mind "refer to a combination of attitudes, dispositions, skills, past experiences, and tendencies for formal and information learning" (ZygourisCoe, 2015, p. 37). Developing a habit of mind specific to STEAM literacy shapes how reading is approached and how students select materials to read. To foster habits of mind in STEAM literacy, students will need to be supported to do the following:

- cognitively and metacognitively associate reading content back to potential STEAM concepts

- actively and critically thinking about what they are reading and how it can be integrated into real-world contexts

- innovatively consider potential applications of knowledge gained from reading by using a critical thinking lens to make connections to the text, self, and world

According to Long II and Davis (2017), literacy "occurs through the process of learning (i.e., deliberate procedure of gaining knowledge) and acquisition (i.e., gaining knowledge through observation, exposure to modelling, imitation, and trial-and-error" (p. 2). To support the process of developing students' STEAM literacy, teachers not only need to be cognizant and mindful of the texts they are incorporating in their STEAM lessons, but they also need to help students learn how to generate good reading habits and develop self-discipline that support STEAM exploration practices. This will support students to become academically successful and knowledgeable about STEAM.

As students engage with their STEAM texts each day, they should be held accountable in efforts to maintain high rigor and nurture their developing habits of mind. An effective way to cultivate reading habits is to increase the exposure to self-directed inquiry practices. In addition, emphasis on scaffolding students' discourse after independently reading self-selected texts can help shape students' repertoires. Grant, Fisher, and Lapp (2015) described a case study where a rich exchange occurred between classroom peers discussing supplemental reading resources utilizing academic language to retrieve and share information that integrated both scientific and real-world issues. In their 
research, Grant and colleagues found that students were not only motivated to read widely due to their ability to choose their texts, but students also learned and used new vocabulary to discuss their ideas. There are several ways to support students to engage in discourse around STEAM topics. In the section that follows a three tiered approach is described.

\subsection{A Three Tiered Approach to Supporting Students'steAm Discourse}

To support students to acquire and integrate the knowledge they have gained from sustained reading of STEAM texts, teachers need to engage students in discourse about what they have read. Table 2 illustrates a generalized set of higher-order thinking topics and questions based on Bloom's taxonomy of action verbs (see Anderson \& Bloom, 2001; Armstrong, 2010) that teachers can use as part of a multi-tiered discourse methods [developed using resources from the NGSs (n.d.) and National Research Council [NRC], 2012] to support students to think about and discuss what they have read.

Teacher can use this table to engage students in a series of discourse activities. The first column indicates action verbs that build ideas, from recalling information to conducting inquiries. Based on these verbs, teachers can enact three tiered approaches to scaffold and deliberately connect students' independent reading content to STEAM knowledge and skill development through discourse - by which students' "ideas are developed and refined" (NRC, 2012, p. 218). The first tier is called turn ' $n$ ' talk, which capitalizes on student-to-student discourse that is not strictly monitored so students gain efficacy and develop their own repertoire among peers. The second tier is called show ' $n$ ' tell, which is where students will share their comprehension of the selected text and share with the teacher for accountability. Through scaffolded questions, stemming from the Bloom's taxonomy continuum, students are prompted to demonstrate connections to STEAM content: Teachers retrieve STEAM-related information by explicitly highlighting discipline-specific content and how students are approaching comprehension and connection. The third tier is called deliver ' $n$ ' build, where students work in large groups to deliver holistic connections they gained from their independent reading, paired with STEAM content covered in class. This activity serves to simultaneously encourage each student while communally fostering their habits of mind and action. In the section that follows, each tier is described in more detail.

\subsubsection{Turn 'n' Talk}

This tier focuses on casual conversations that have specific topics highlighting key points that refer to the multimodal text students are reading and aiming to make STEAM connections. Table 2 illustrates brief examples of turn ' $n$ ' talk 


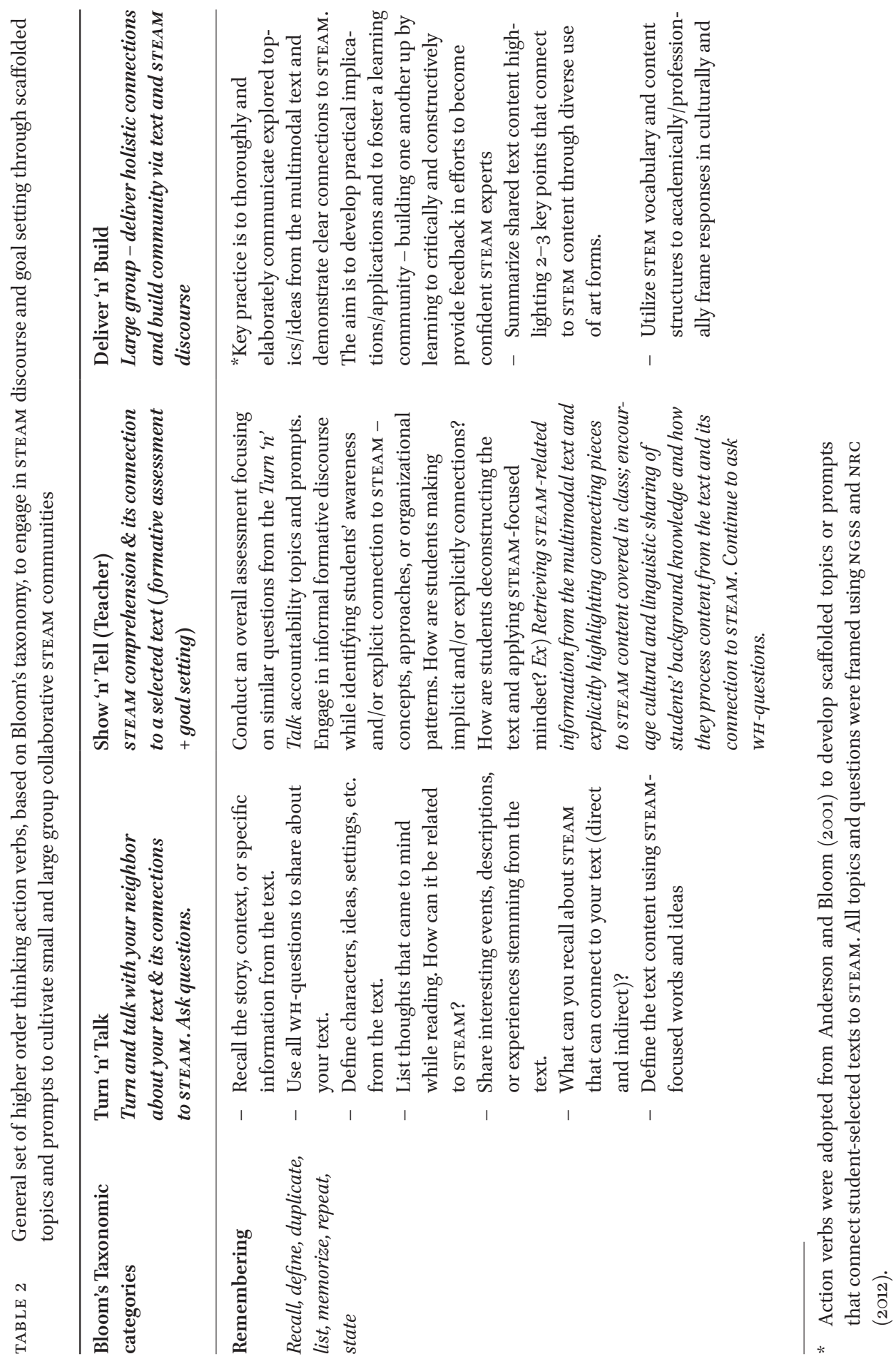


0
0
0
0
0
0
0
0
0
0
0
0
0
0
0
0
0
0
0
0
0
0
0
0
0
0
0
0
5
0
0
0
0
0

(5)

害

छิ

苋

क

हี่

일

ฮี สำ

总

के

离

:

:

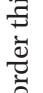

๖े 용

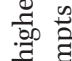

प्ञ⿰冫欠

峁

$\begin{array}{ll}\pi & \pi \\ 0 & 0 \\ 0 & 0 \\ 0 & 0\end{array}$

N

똔

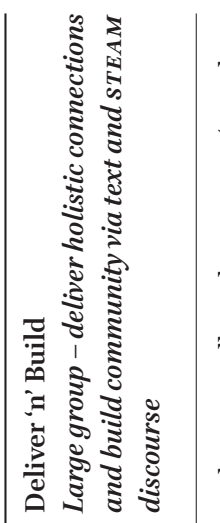

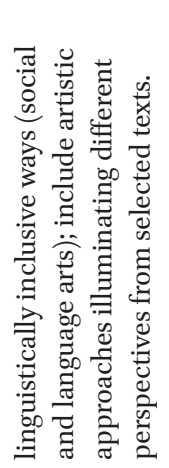

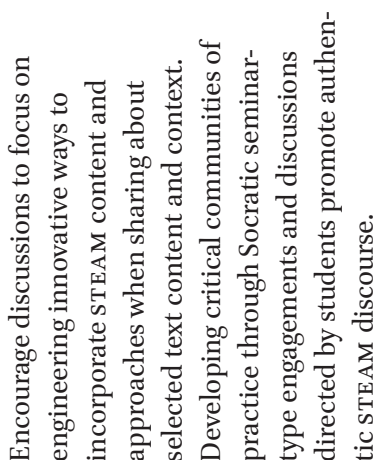

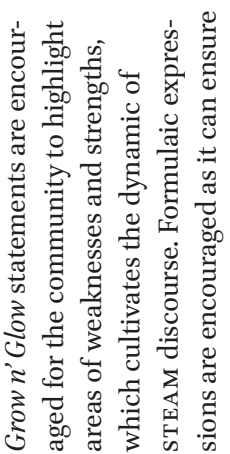

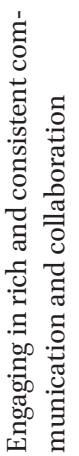

过 항 ส

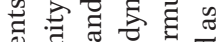
घี

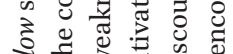
心

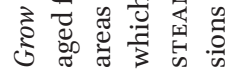

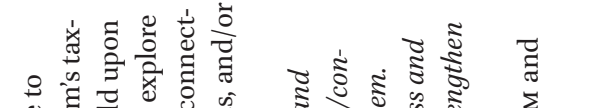

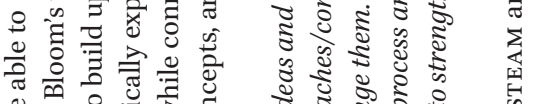
党

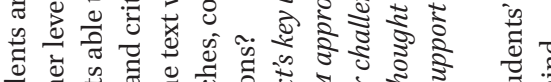

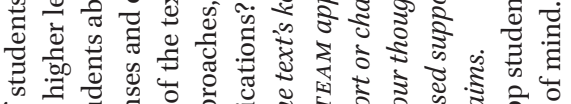
क द ज

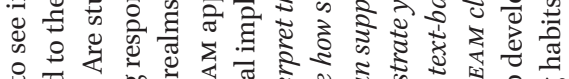

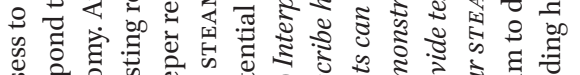

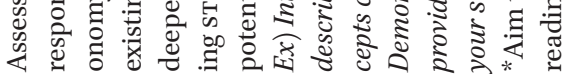

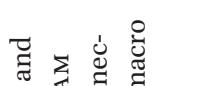

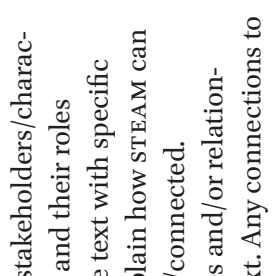

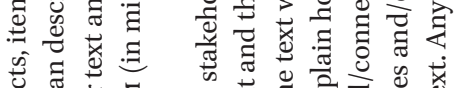

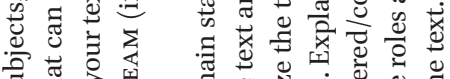

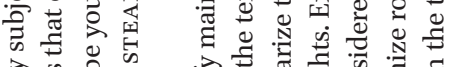

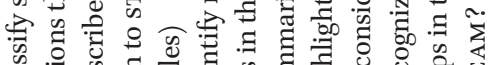

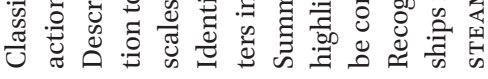

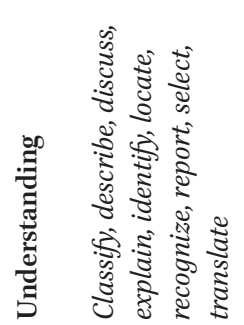
热㣂

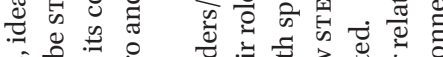

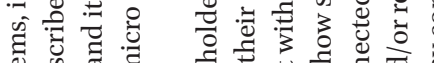

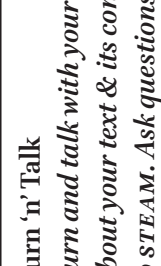
E 


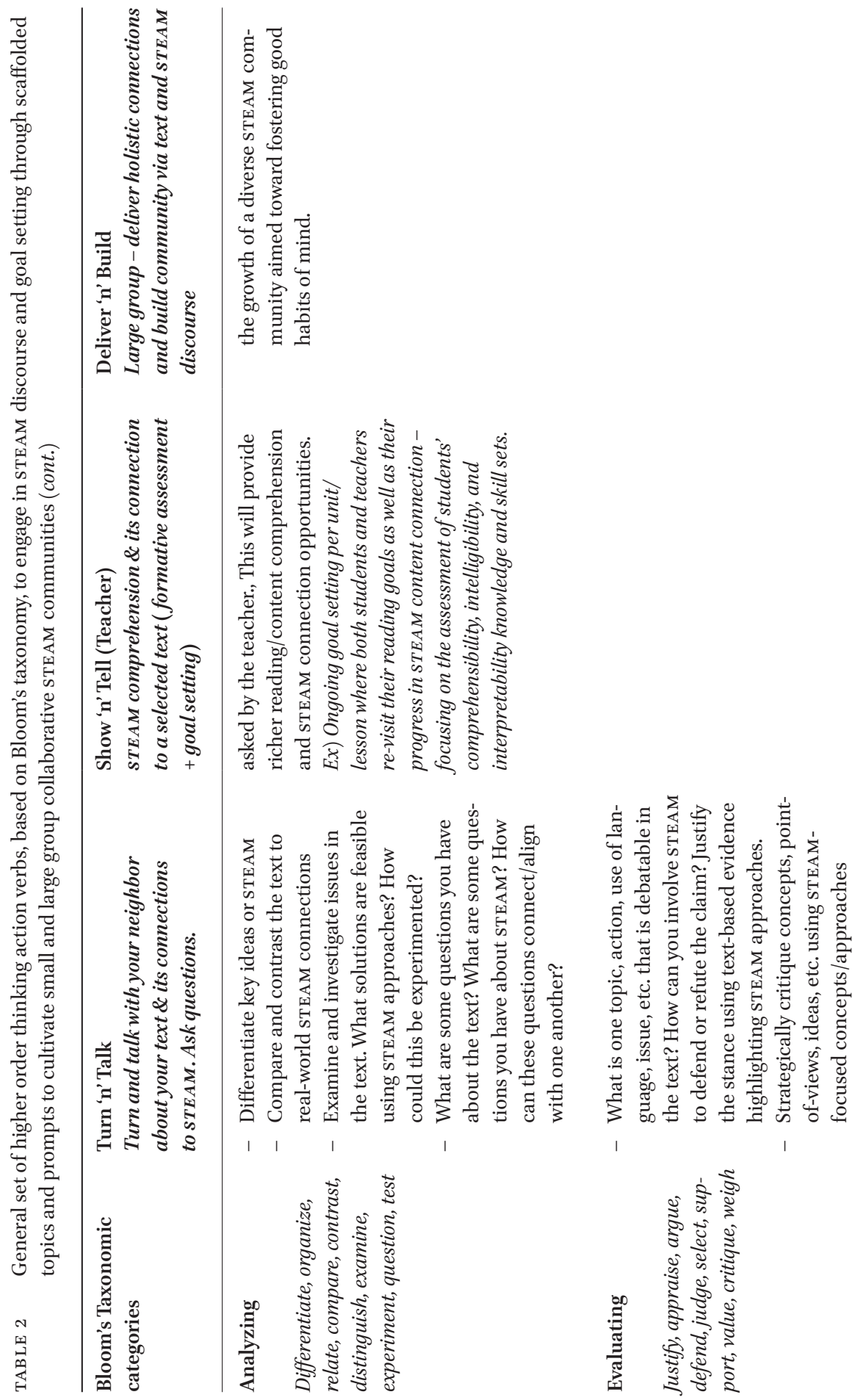



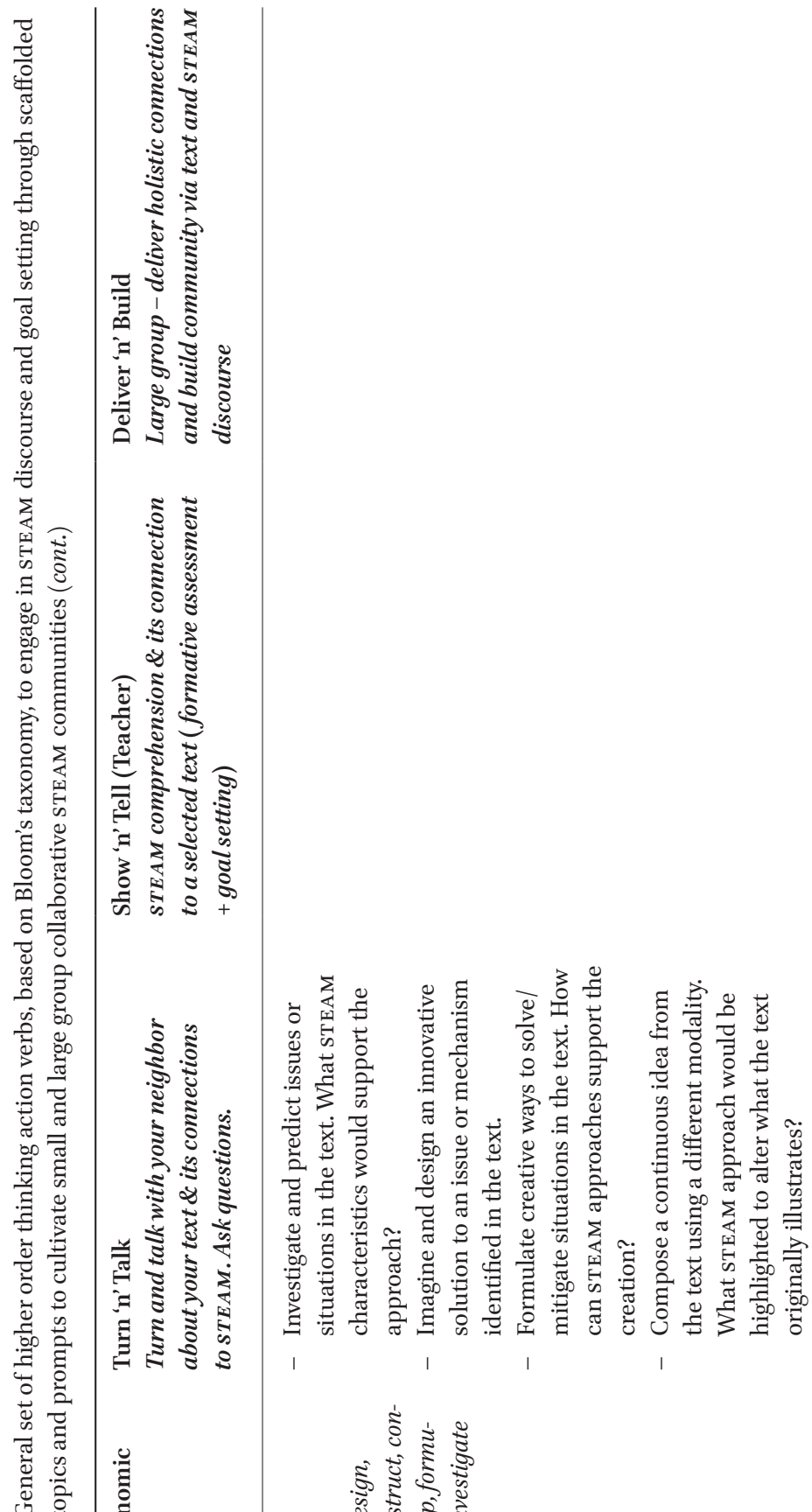

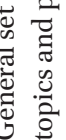

N
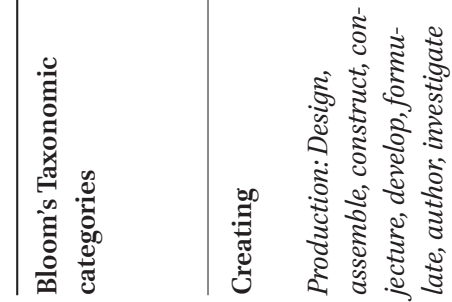
themes and strategies that focus on explicitly connecting students' discourses to STEAM. This approach allows for peer-based scaffolding to take place as students begin dissecting their texts and asking higher-order cognitive thinking questions together. The discourse that takes place generates space for students to begin practicing active and critical thinking skills as they creatively engage with their selected text and STEAM content - both introductory and advanced. This practice develops the early stages of acquiring STEAM repertoire and accountability for the development of STEAM habits of mind. Osborne (n.d.) states that reading is key to accessing and employing knowledge and supports additional scientific skills, such as tracing the key steps in a procedure, "cit[ing] evidence to draw inferences, formulat[ing] hypotheses, and support[ing] or critique[ing] arguments" (para. 2). Thus, the intention is for students to retrieve what they gained from their readings and further apply it to enrich literacy, STEAM, and content-focused peer discourse development.

\subsubsection{Show ' $n$ ' Tell (Teacher)}

This tier primarily focuses on the group-to-one or one-on-one encounters where teachers take the time to monitor students' reading progress and provide support along with encouragement where necessary. This process allows teachers to formatively assess students' reading comprehension. This step provides a second level accountability for each student so that the sustained reading time is productive. The goal is for students to gradually reach feasible zones of proximal development (Vygotsky, 1962) where their habits of mind are developed to always consider everyday mechanisms and outcomes through a STEAM lens. To reiterate, the arts component of STEM is crucial here as students are creatively making relevant and meaningful connections by scaffolding their comprehension of the multimodal text to their growing STEM schema. Scaffolding is necessary as it creates a bridge for student success when strongly tied to "the intended function of the strategy and the context in which it [is] used" (Belland, 2017, p. 25). According to Belland (2012), scaffolding is crucial as it helps students gain skills and abilities to "investigate complex scientific phenomena" (p. 9o), authentically engaging in argumentation through the formulation of claims, warrants, evidence and counter evidence. This tier can be employed as an ongoing portfolio for students in efforts to gain greater STEAM literacy. Along with formulating gradual goals, this STEAM portfolio can provide a holistic analysis of their knowledge and skill sets, as well as guiding teachers on how to assess, build, and co-develop goals with students. This makes room for literacy expansion where all participants continually challenge each other and engage in higher-order thinking processes together. 


\subsubsection{Deliver 'n' Build}

The third tier focuses more on communication and collaboration. Students learn how to consolidate their discussed points from the first two tiers and structure them into clear and concise statements to share with larger groups. Underscoring two to three key points, students are asked to share connections their text has to STEAM along with potential discoveries, additional insights, critical questions, predictions, or conclusions they considered. As a collaborative discursive practice, any form of encouragement and feedback is accentuated (e.g., sandwich feedback method) to support the growth of the group presenter as well as the class. Conclusively, a community-building technique is suggested, called Grow ' $n$ ' Glow, to cultivate an encouraging and empowering environment among students who collaboratively strive toward achieving set goals formed in the second tier.

\subsection{Reading Strategies and Habits of Mind to Develop Students' STEAM Literacy}

The implementation of the three tiers is contingent upon the teacher and the allotted time. An example of how this would work in the classroom is that students would be provided the space to read their self-selected book for 10-15 minutes per class period for two weeks. This activity would then be followed up with a week of engaging with their peers (setting the same allotted time) for close accountability and alignment with all students. Developing habits of mind and reading strategies must be consistently and strategically developed; it is not innately formed overnight. In addition, great intention, exposure, and support is needed for students to gradually learn how to engage with multimodal texts effectively. The scaffolded questions embedded in the teaching and learning framework of in-class STEAM reading will provide an encouraging environment for students to engage in this enterprise.

The planned and executed tiered procedures are good habits to instill in students who are struggling to persist in reading. In addition, they support greater reading comprehension, accountability with reading goals, and opportunities to communicate integrated thoughts to others. Hsui's (2000) research on reading revealed that giving students "ownership over the materials [they] choose to read and are allowed to read in a relaxed, non-judgmental environment within the classroom has mostly shown that these activities contribute to the development of independent reading and language learning" (p. 31). However, it is expected that students' growth in independent reading, using Bloom's taxonomy to critically question texts, will inevitably diffuse into being able to analyze texts that can be applied to STEAM content learning over time. 
Studies on the coupling of STEAM and literacy are scarce, which may be due to challenges in defining the pedagogy of STEAM and how the arts are incorporated. A potential solution to this has been established using another acronym to encompass the importance of literacy development, incorporating the " $\mathrm{R}$ " for reading: STREAM. However, this detracts from the core focus of STEAM and promoting literacy across disciplines in an integrative manner. Literacy is the foundation of STEAM education and is integrated as an essential component of STEAM practice. As this paper has suggested, developing STEAM literacy through initiated self-selected reading time during class, supported by tiered scaffolded STEAM discourse, provides great opportunities for students to autonomously reading to learn. Overall, literacy has an impact on STEAM in a plethora of ways, whether it is "kids [who] are learning how to build something, conduct[ing] a science experiment, or cod[ing] a computer program, strong reading skills help process and interpret text [to] better follow instructions and understand what to do" (Scholastic Parents Staff, 2020, para. 2).

Reading is a large part of STEAM learning, and experts in STEAM pedagogy constantly seek literature to guide their understanding, puzzling pieces together and adapting a variety of mechanisms to problematize real-world STEAM settings. The unifying crux of STEAM is literacy where scientific practices entail the process of investigating, engineering, and proposing solutions based on historical trial-and-error experimentations. Reading literacy is considered one of the top skills needed to navigate the greater STEAM economy and a generalized key to achieving important milestones, personally and professionally (Ferrari, 2020). Reading literacy feeds into STEAM literacy, which supports the development of knowledge and skill sets, for example, mathematical problem solving, technological troubleshooting, and communicating scientific findings to diverse audiences. The pathway to STEAM literacy is through reading and writing. Grant, Fisher, and Lapp (2015) explicitly mentioned the tightknit practice demonstrated by scientists, stating that

most scientists in the "real world" read and write daily as part of their jobs. They write grants, notes, reports, and articles. They hypothesize, take notes, and collect and organize information. They closely read and critique the word of others, and they also critically read their own work ... scientists like to be informed, which requires that they read from a variety of sources in their discipline. (p. 18) 
The word "read" appears four times in this quote, reinforcing the point that scientists must be well-informed individuals through reading. Their literacy must continuously be developed and practiced through reading and discourse practices - including, as the quotation above mentions, writing. The authors continue by mentioning how a disservice is done to students in classrooms by referring them to a single source, most often a textbook; premade worksheets and structured labs also fall in this category. Although these are quite beneficial for students based on the implementation of various reading strategies, STEAM investigations ideally involve accessing multiple sources to holistically shape one's understanding of concepts. Therefore, the symbiotic relationship between STEAM and reading illustrates greater opportunities for students to explore and engage to both widen and deepen their schemas by experiencing, asking questions, and interacting with various STEAM texts (Grant, Fisher, \& Lapp, 2015). The connection this paper seeks to introduce and begin to spark further interest is the use of literacy in STEAM through the lens of sociocultural aspects that highlight specific demographic categories that are often times misrepresented or selectively represented in STEM. The following section finalizes the paper revisiting the ways in which sт EAM literacy issues impact on language learners and how the lack of disaggregated STEM data about students of the Asian diaspora in the United States makes invisible the challenges that some Asian immigrants and Asia American students may face in STEM.

The purpose of developing this teaching and learning framework focused on self-selected multimodal text reading practices in the classroom is to support all students, but more specifically to focus on supporting language learners and learners with specific needs and specific modality preferences. The framework promotes the opportunity and support for learners to dive into STEM from multiple angles in multilingual and multicultural ways, which is encompassed in the arts. This is an increasingly necessary pedagogy as the U.S. exponentially globalizes, diversifying its demographics. According to the Funk and Parker (2018), the single-race, non-Hispanic Asian population in the U.S. doubled in 2019, to 22.4 million, making Asians one of the fastest growing racial groups in the country (Lau, 2020). In 2017, ten of the most populous states had the highest demographic of Asians, including California, New York, Texas, New Jersey, Illinois, Washington, Florida, Virginia, Hawaii, and Massachusetts (Office of Minority Health [омн], 2019). When examining statistics related to college, career, and STEM, "Asians" appear to be disproportionately overrepresented in 
multiple categories, relative to their overall share of the workforce. For example, census data found that $86.9 \%$ of Asians and Asian Americans 25 years and older had at least a high school diploma $(\mathrm{OMH}, 2019)$ and roughly $83 \%$ were likely to have a bachelor's degree in STEM compared to their White counterparts (Funk \& Parker, 2018). When looking at ST EM careers, another study found that Asians who pursued doctoral degrees in STEM fields were predominantly East Asian students, such as Korean (31.1\%) and Taiwanese (40\%) citizens (Her, 2019). According to McGee (2018), "Asians are typically situated at the top of the Sтем educational and career hierarchy" (p. 1). Despite these statistics, some essential questions are not being posed, such as who is considered "Asian"? Is the Asian demographic one entity? This kind of aggregated data presents the Asian diaspora as monolithic, which perpetuates the model minority myth that characterizes Asian and Asian American communities as "docile", "good at math", and "naturally" excelling in sт E m fields. Research, however, is needed to shed light on the underrepresented and invisible individuals that make up the diaspora that struggle to even consider STEM as a career opportunity. Many students of the Asian diaspora face challenges in school and in STEM that could be addressed by strategies like the ones described in this paper to promote STEAM literacy, which could provide opportunities for all Asians and Asian Americans to see themselves in the curriculum and career fields.

The ways in which the Asian diaspora is currently represented in national reports continuously perpetuate the belief that all Asians are performing well in schools and STEM. If data was appropriately disaggregated it would illuminate significantly lower rates of achievement in some Asian and Asian American subgroups (Lau, 2020). According to the Budiman and Ruiz (2017), 22 million Asians and Asian Americans have family origins in more than 20 Asian countries. Asian and Asian American communities include people from East Asia (China, Korea, Japan, and Taiwan), Southeast Asia (Burma, Cambodia, Philippines, Indonesia, Laos, Thailand, and Vietnam), and South Asia (Afghanistan, Bangladesh, Bhutan, India, Nepal, Pakistan, Sri Lanka, and the Maldives). Disparity exists among Asians and Asian Americans who "fit the model minority stereotype" (Chai \& Weseley, 2017, p. 45) and those who do not. Generally, the model minority describes only the visible high achievements of Asians and Asian Americans, which gives a false picture that overgeneralizes the success of all Asians (Kasinitz, 2011). These blanket perceptions, coupled with racial prejudices, can lead to negative re/actions toward Asians and Asian Americans in STEM fields. The model minority stereotype harms Asians and Asian Americans who are perceived as a homogenous group of model minorities that apparently have the "knowledge" and "skill sets" to achieve STEM 
curriculum and fields, and also the under-supported "outcast" group who do not fit the model minority stereotype and thus fall through the cracks becoming invisible and negatively mislabeled.

Research on the Asian diaspora in the United States shows that many individuals speak a language other than English in the home. According to aggregated data summarized by Ramakrishnan and Ahmad (2014), the Asian population in the United States represents the largest percentage of individuals with limited English-proficiency (35\%) of all groups. Further analysis showed that the percentage of Asian households experiencing linguistic isolation (meaning a household with only one person 14 years or older able to speak English exclusively or "very well") is $20 \%$, meaning one in every five Asian and Asian American households, which is similar to Latino/Hispanic households (Ramakrishnan \& Ahmad, 2014, p. 4-5). Knowing such a large portion of the Asian and Asian American communities are composed of language learners highlights the fact that STEM education must be sensitive and conducive to the linguistic and cultural richness Asians and Asian Americans present in classrooms. Greater linguistic support is needed to cultivate the development of students' bi/multilingualism and multiculturalism, capitalizing on Asians and Asian Americans' diverse strengths in order to gain holistic proficiency in English language literacy and STEAM literacy.

As globalization gains momentum, the development of autonomous and adaptable learning structures is essential to learners. As the United States has a rapidly growing population of Asian and Asian American language learners in STEAM classrooms, it is essential to support these language learners in relevant and well-contextualized ways. Scaffolded reading approaches highlighting diversity, equity, and inclusion through the arts support learners in both social (basic interpersonal communication skills) and academic (cognitive academic language proficiency) repertoires. Especially with Asian and Asian American students straddling generationally adopted cultural practices and/or embracing stereotyped characteristics of not asking questions and being "shy" in class, the tiered practice of self-selected multimodal texts and using effective discursive strategies cultivates inclusion, self-efficacy, motivation, and interest. It encourages and empowers students to collaborate and find innovative ways to correlate diverse readings with STEAM, which takes advantage of the potential all Asians and Asian Americans offer through rich linguistic and cultural approaches to STEAM topics.

It is crucial to consider the development of the reading language domain. Reading has tremendous applicable benefits to STEAM education, yet it is rarely considered when discussing and implementing its practices, especially with Asian and Asian American students. Skilled and active readers use critical 
cognitive and metacognitive strategies that support academic achievement overall. Reading activates cross-linguistic transfer of skills needed to preview, predict, make inferences, draw from background knowledge, and summarize (O'Reilly \& McNamara, 2002). In addition, students encounter greater opportunities to analyze, evaluate, synthesize, and critique information from varying sources (Scott \& Saaiman, 2016). Correlating with one of STEAm's pillars, providing opportunities for students to engage in reading inherently supports social interactions and diversifies avenues in which sharing their explorations becomes more contextualized and cohesive. This teaching and learning framework structures an approach that allots Asian and Asian American students opportunities to independently explore their interests first through the arts before endeavoring into more dense STEM materials, allowing for greater comprehensible input and intrinsic interest. This optimal input through self-selected and scaffolded practices ultimately supports both native and non-native speakers to learn STEAM and gain STEAM literacy. Through the strong tiered support fostering intentional steAm discourse, Asian and Asian American students have diversified chances to enhance perspectives, ideas, and approaches to STEAM that fully embrace and appropriately represent all learners in the STEM curriculum and careers that are initiated and sustained through the arts.

The nature of this teaching and learning framework, emphasized in grade schools, poses many limitations to a new strategy of STEAM education and literacy. The limitations lie primarily in the feasibility, in terms of limitations on time outside of the pressures of achieving set standards, of teachers' gaining higher self-efficacy to flexibly integrate STEM content through diverse approaches that capitalize on students' funds of knowledge influenced by lived experiences outside of the classroom. In addition, there may be limitations on teachers' willingness to co-construct reading practices in the classroom that focus on developing STEM knowledge through the power of reading and the arts. Making the time to read every class period and taking part in the tiered teaching and learning practices also requires scaffolded professional development for the teachers. Otherwise, the pedagogy reverts back to the arts being a simple add-on to the siloed ST EM content delivery, followed by robotic participation through prescribed STEM work. These limitations greatly hinder the development of inclusively diverse approaches to STEAM-based investigations in class, for both teachers and the students. There are great socio-cultural, 
linguistic, historical, and political factors that need to be acknowledged and considered when approaching various STEM topics, especially highlighting the integration of the arts, which sustains the way all students can be well represented in the globally recognized ST EM field.

Another limitation is the set infrastructures that limit the development of a STEAM library, either in class or as a communal resource cart, which should contain multimodal texts such as trade books, magazines, audiovisuals, and kinesthetic manipulatives. To continually present STEM as inclusive, a greater number of resources that highlight the assets of all cultures and languages that shape STEM is essential, which can be highlighted only through the integration of the arts. This focus can be a great limitation since STEM content is technical, dense, and unidimensional in its presentation; traditional practices tend to be perpetuated in the texts that are frequently presented in STEM content. This can confine the way teachers perceive multimodal texts and make appropriate selections for students to choose from, which can also limit students' exposure to a larger range of inclusive and varied resources.

There is great potential in purposively integrating literacy and STEAM teaching and learning practices that support students to become world-class experts in the fields of science, technology, engineering, the arts, and math; not just for developing disciplinary knowledge but for holistically developing other globally useful skill sets - critical thinking, innovative problem solving, collaborative reasoning, and intercultural discourse. Instructing STEAM through literacy practices scaffolded in the classroom has great potential to go beyond the classroom walls; students will gain the agency to seize a variety of diverse opportunities through their sharpened independent reading habits - of mind and action. The practice of providing students self-selected independent reading time and space, along with intentionally rigorous yet thoroughly scaffolded techniques supported in three tiers ultimately shapes self-directed and selfsustained individuals, who carry on these practices as they become life-long learners. The hope is that this teaching and learning framework will encourage teachers to not only create a classroom STEAM library utilizing criteria focused on inclusive and rigorous STEAM content, both for teachers and students, but to also loosen the reins on how students explore the world. Independent reading and self-exploration enhanced by higher-order thinking discourses spur on greater interests and connections along with deeper conversations. This is the development of STEAM literacy. Although further research on and application 
of this learning-by-reading approach is in order, interdisciplinary teaching and learning through reading is an important step to eliciting greater cognitive development, creativity, connection, and autonomy in STEAM.

\author{
Abbreviations \\ CCR College and career readiness anchors \\ ccss Common Core State Standards \\ NGSS Next Generation Science Standards \\ ScSR Scaffolded Silent Reading \\ SSR Sustained STEAm Reading \\ StEAM Science, Technology, Engineering, the Arts, and Math \\ STEM Science, Technology, Engineering, and Math \\ STREAM Science, technology, reading, engineering, arts, and math
}

\title{
Ethical Consideration
}

The data reported in this study does not require human subjects' approval.

\section{About the Author}

Jennifer Park received her doctoral degree in Science Education from Seoul National University. Currently she is a lecturer at the University of Southern California. Her clinical teaching role in the MAT-TESOL program focuses on social and cultural foundations in language education and its influences on content-based pedagogical approaches. She continues to seek avenues to ensure greater integration between language and science education in efforts to provide ample support for language learners to gain proficiency in both fields of literacy.

\section{References}

Anderson, L. W., \& Bloom, B. S. (2001). A taxonomy for learning, teaching, and assessing: A revision of Bloom's taxonomy of educational objectives. Longman.

Armstrong, P. (2010). Bloom's Taxonomy. Vanderbilt University Center for Teaching. Retrieved from https://cft.vanderbilt.edu/guides-sub-pages/blooms-taxonomy. 
Atkinson, T. S., Matusevich, M. N., \& Huber, L. (2009). Making science trade book choices for elementary classrooms. The Reading Teacher, 62(6), 484-497.

Belland, B. R. (2012). Habitus, scaffolding, and problem-based learning: Why teachers' experiences as students matter. In S. B. Fee \& B. R. Belland (Eds.), The role of criticism in understanding problem solving: Honoring the work of John C. Belland (pp. 87-100). New York: Springer.

Belland, B. R. (2017). Instructional Scaffolding in STEM Education: Strategies and Efficacy Evidence. Springer. https://doi.org/10.1007/978-3-319-02565-O_2.

Budiman, A., \& Ruiz, N. G. (2017 April 29). Key facts about Asian Americans, a diverse and growing population. Pew Research Center. Retrieved at https://www.pew research.org/fact-tank/2021/o4/29/key-facts-about-asian-americans/.

Buxton, C., \& Austin, P. (2003). Better books, better teaching. Science and Children, $41(2), 28-32$.

California Department of Education [CDE] (2013). California Common Core State Standards (CCSS): English Language Arts and Literacy in History/Social Studies, Science, and Technical Subjects. Retrieved from https://www.cde.ca.gov/be/st/ss/ documents/finalelaccssstandards.pdf.

Chai, D. \& Weseley, A. J. (2017). Is STEM running out of steam for Asian Americans? College admissions officers' perceptions of applicants. Asian Journal of Social Psychology, 20, 45-53.

Chu, H.-E., Martin, S. N., \& Park, J. (2018). A theoretical framework for developing an intercultural STEAM program for Australian and Korean students to enhance science teaching and learning. International Journal of Science and Mathematics Education, 17, pp. 1251-1266. DoI https://doi.org/10.1007/s10763-018-9922-y.

Cox, C. (2012). What the research says about literature-based teaching and science. Reading Rockets. Retrieved at https://www.readingrockets.org/article/what-research -says-about-literature-based-teaching-and-science.

Dell'Erba, M. (2019). Preparing students for learning, work and life through STEAM education. Arts Education Partnership. Education Commission of the States. Retrieved at https://www.ecs.org/wp-content/uploads/Preparing-Students-for-Lear ning-Work-and-Life-through-STEAM-Education.pdf.

Department of Defense Education Activity [DDEA] (n.d). College and Career Readiness (CCR) Standards: Literacy. Retrieved from https://www.dodea.edu/college careerready/ela-standards.cfm.

Donovan, C., \& Smolkin, L. (2002). Considering genre, content, and visual features in the selection of trade books for science instruction. The Reading Teacher, 55(6), $502-520$.

Ferrari, P. (2020 April 28). Trends in learning: STEM, STEAM, STREAM ... a battle of acronyms? cApStAn: Linguistic Quality Control. Retrieved from https://www .capstan.be/trends-in-learning-stem-steam-stream-a-battle-of-acronyms/. 
Funk, C., \& Parker, K. (2019 January 9). Diversity in the STEM workforce varies widely across jobs. Pew Research Center. Retrieved from https://www.pewresearch.org/ social-trends/2018/o1/og/diversity-in-the-stem-workforce-varies-widely-across-jobs/.

Grant, M. C., Fisher, D., \& Lapp, D. (2015). Reading and writing in science: Tools to develop disciplinary literacy. Sage Publications: Thousand Oaks, CA.

Hadler, P. (2015, December 19). 7 sustained silent reading (SSR) strategies. Global Educator Institute. Retrieved from http://geiendorsed.com/blog/curriculum/7-sus tained-silent-reading-ssr-strategies/.

Her, T. (2019). The underrepresentation of Hmong American college students in STEM majors [Unpublished doctoral dissertation]. California State University, Fresno.

Hsui, V. Y. (2000). Guided independent reading (GIR): A program to nurture lifelong readers. Teaching \& Learning, 20(2), 31-39.

Hwang, J., \& Taylor, J. C. (2016). Stemming on STEM: A STEM education framework for students with disabilities. Journal of Science Education, 19(1), pp. 39-49.

Kasinitz, P. (2011). Model minority. Retrieved from https://depts.washington.edu/sibl/ Publications/Model\%2oMinority\%2oSection\%2o(2011).pdf.

Kaczmarek, S. (2016). Why STEM and reading go hand in hand. Reading Partners. Retrieved from https://readingpartners.org/blog/why-stem-and-reading-go-handin-hand/.

Krashen, S. (April 2004). Free voluntary reading: New research, applications, and controversies. Paper presented at RELC Conference, Singapore. Retrieved from http:// www.sdkrashen.com/content/articles/singapore.pdf.

Lau, T. (2020 April 2). 2020 Census: What's at stake for Asian Americans and Pacific Islanders? Brennan Center for Justice. Retrieved from https://www.brennancenter .org/our-work/analysis-opinion/2O2O-census-whats-stake-asian-americans-and -pacific-islanders.

Long II, R. L., \& Davis, S. S. (2017). Using STEAM to increase engagement and literacy across disciplines. The STEAM Journal, 3(1), pp. 1-11.

May, G. S. (2015). STEM, not STEAM. Inside Higher Ed. Retrieved from https:// www.insidehighered.com/views/2015/o3/30/essay-criticizes-idea-adding-arts-push -stem-education.

McGee, E. (2018). "Black genius, Asian fail": The detriment of stereotype lift and stereotype threat in high-achieving Asian and Black STEM students. American Educational Research Association. https://doi.org/10.1177/2332858418816658.

Meyers, R. (1998). Uninterrupted sustained silent reading (EDSE 695). [Exit Project, California State University Long Beach]. ERIC. Retrieved from https://files.eric. ed.gov/fulltext/ED418379.pdf.

Milgrom-Elcott, T. (2019). When STEM becomes STEAM, we can change the game. Forbes. Accessed from https://www.forbes.com/sites/taliamilgromelcott/2019/11 /o7/when-stem-becomes-steam-we-can-change-the-game/?sh=41b5929c69o5. 
Mpofu, V. (2019). A theoretical framework for implementing STEM education. Retrieved from https://www.intecho pen.com/chapters/68740.

National Council for Teachers of English (NCTE). (2013). NCTE framework for 21st century curriculum and assessment. Retrieved from https://cdn.ncte.org/nctefiles/ resources/positions/framework_21stcent_curr_assessment.pdf.

National Research Council [NRC]. (2012). A framework for K-12 science education: Practices, crosscutting concepts, and core ideas. The National Academies Press: Washington D.C.

National Science Teaching Association (NSTA). (2012). Position statement. STEM Education Teaching and Learning. Retrieved from https://www.nsta.org/nstas -official-positions/stem-education-teaching-and-learning.

Next Generation Science Standards (NGss). (n.d.). The three dimensions of science learning. Retrieved from https://www.nextgenscience.org/.

Office of Minority Health [омн]. (2019). Profile: Asian Americans. U.S. Department of Health and Human Services. https://minorityhealth.hhs.gov/omh/browse.aspx ?lvl $=3 \&$ slvlid $=63$.

O'Reilly, T., \& McNamara, D. S. (2002). What's a science student to do? Proceedings of the Annual Meeting of the Cognitive Science Society, 24(24). Retrieved from https:// escholarship.org/uc/item/2jcit41v.

Osborne, J. (n.d.). Reading to learn in science. Stanford Graduate School of Education. Retrieved from https://online.stanford.edu/courses/gse-yoo26-reading-learn -science.

Quigley, C. F., \& Herro, D. (2016). "Finding the joy in the unknown": Implementation of STEAM teaching practices in middle school science and math classrooms. Journal of Science Education and Technology, 25, 410-426.

Ramakrishnan, K., \& Ahmad, F. Z. (2014). Language diversity and English proficiency: Part of the "state of Asian Americans and Pacific Islanders" series. Center for American Progress. Retrieved from https://cdn.americanprogress.org/wp-content/ uploads/2014/o4/AAPI-LanguageAccessi.pdf.

Reutzel, D. R., Jones, C. D., Fawson, P. C., \& Smith, J. A. (2008). Scaffolded silent reading: A complement to guided repeated oral reading the works! The Reading Teacher, 62(3), 194-207.

Scholastic Parents Staff. (2020). How reading skills help kids thrive in STEAM subjects: Plus, ten activities that will boost your child's success in both. Scholastic Parents. Retrieved from https://www.scholastic.com/parents/books-and-reading/raise-areader-blog/reading-steam-education.html.

Scott, L., \& Saaiman, E. (2016 Aug 13). Promoting reading skills or wasting time? Students' perceived benefits of reading in an intermediary programme at the Vaal University of Technology. Reading \& Writing - Journal of the Reading Association of South Africa, 7(1), a82. http://dx.doi.org/10.4102/ rw.v7i1.82. 
Victoria State Government. (2018). Literacy teaching toolkit: Multimodal Literacy. Retrieved from https://www.education.vic.gov.au/school/teachers/teachingresour ces/discipline/english/literacy/readingviewing/Pages/litfocusmultimodal.aspx.

Von Sprecken, D., \& Krashen, S. (1998). Do students read during sustained silent reading? The California Reader 32(1):11-13.

Vygotsky, L. S. (1962). Thought and language. Cambridge, MA: MIT Press.

Yakman, G. (2008). STE@M Education: An overview of creating a model of integrative education. Retrieved from http://steamedu.com/wp-content/uploads/2014/12/ 2008-PATT-Publication-STEAM.pdf.

Yakman, G. (2012). Recognizing the A in STEM education. Middle Ground. Retrieved from http://www.steamedu.com/wp-content/uploads/2014/12/YakmanSTEAM. MiddleGround2012.pdf.

Zygouris-Coe, V. I. (2015). Discipline-specific literacies in grades 6-12: Preparing students for college, career, and workforce demands. Routledge: New York. 